\title{
MCTD WITH LARGE VASCULITIC ULCERS- A THERAPEUTIC DILEMMA
}

\author{
Pranit V. Farande1, Sunil Petkar ${ }^{2}$, Aishwarya Khandge 3
}

${ }_{1}^{1}$ Assistant Professor, Department of Dermatology and Venereology, Terna Medical College, Nerul.

2 Professor, Department of Dermatology and Venereology, Terna Medical College, Nerul.

${ }^{3}$ Resident, Department of Dermatology and Venereology, Terna Medical College, Nerul.

HOW TO CITE THIS ARTICLE: Farande PV, Petkar S, Khandge A. MCTD with large vasculitic ulcers- a therapeutic dilemma. J. Evolution Med. Dent. Sci. 2017;6(83):5825-5827, DOI: 10.14260/jemds/2017/1265

\section{PRESENTATION OF CASE}

A 37 years old female, a homemaker, residing in Navi Mumbai, came with chief complaints of multiple painful, reddish black skin lesions with blisters since 2 days, fever since 15 days, ulcer over fingertips since 3 months, tightening of skin over face since 3 months.

Patient was apparently alright about 3 months before when she first presented to us with complaints of bluish discoloration of her fingers on exposure to cold. On rewarming, the fingers used to become normal. This was followed by development of small ulcers over the fingertips, which later healed with stellate scars. About 3 months ago, she developed pain in the knee joints. The pain subsided temporarily by the analgesics prescribed by the local practitioner. She also developed swelling of hands and feet and tightening of her facial skin. About 15 days ago, she developed fever. It was of high grade and continuous type, subsiding temporarily with antipyretics. After a few days following the onset of fever she developed painful, reddishblack skin discoloration of skin over the left hand dorsum, right elbow and forearm and the right calf area. The painful discoloration rapidly increased in size and developed reddish fluid filled blisters. There was history of decreased appetite and weight loss. There was no history of photosensitivity, difficulty in swallowing, breathing or other systemic involvement. There was no history suggestive of any neurological or musculoskeletal impairment and urinary bladder disturbance. Past history was not significant. There was no history of drug allergy, medical or surgical illness. Menstrual history $-3 / 28$ days regular menstrual cycle. Attained menarche at the age of 17 years of age. Obstetric history- She has three children, all were full-term normal deliveries without any complications. She did not have any history of abortions.

\section{General Examination}

Patient was conscious, well-oriented to time, place and person. She was febrile. Her vitals were normal. She had moderate pallor and oedema of hands and both feet. Cutaneous examination revealed multiple areas of cutaneous necrosis in the form of indurated purpuric red skin with multiple haemorrhagic blisters.

'Financial or Other Competing Interest': None.

Submission 25-09-2017, Peer Review 07-10-2017,

Acceptance 09-10-2017, Published 16-10-2017.

Corresponding Author:

Pranit V. Farande,

Flat 3, Nishant Kutir CHS

Plot 216, Sector 28, Vashi

Navi Mumbai.

E-mail: fpranit@gmail.com

DOI: $10.14260 /$ jemds $/ 2017 / 1265$

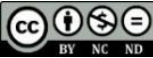

Right lower extremity was extensively involved with lesion over the right leg, wherein whole of the posterior calf region was involved extending up to the lower half of the right thigh. The border appeared irregular and geographic. Skin surrounding the ulcer was erythematous, tender and indurated. Identical lesions were seen on left hand dorsum, right elbow and forearm. All mucosae were normal. Systemic examination was normal.

\section{CLINICAL DIAGNOSIS}

We kept a provisional diagnosis of Mixed Connective Tissue Disorder with Vasculitis.

\section{Investigations}

She was investigated. She had anaemia, leucocytosis and thrombocytosis. The serial reports done showed declining haemoglobin levels, but leucocytosis getting improved.

\begin{tabular}{|c|c|c|c|}
\hline Date & Hb (gm\%) & WBC (Cum.) & Platelet (Lakhs) \\
\hline $31-03-17$ & 13.1 & 35,000 & 3.21 \\
\hline $03-04-17$ & 8.3 & 21,800 & 3.24 \\
\hline $09-04-17$ & 8.4 & 16,900 & 1.97 \\
\hline $15-04-17$ & 7.8 & 16,300 & 3.33 \\
\hline $19-04-17$ & 8.1 & 16,400 & 8.90 \\
\hline
\end{tabular}

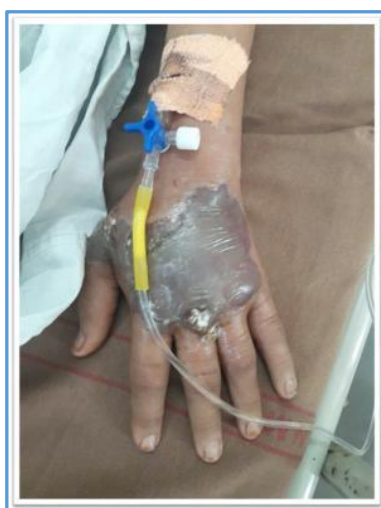

Figure 1

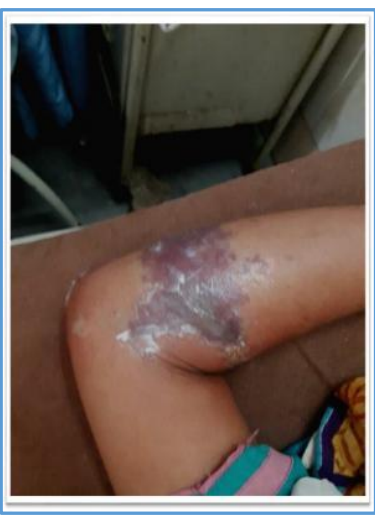

Figure 2

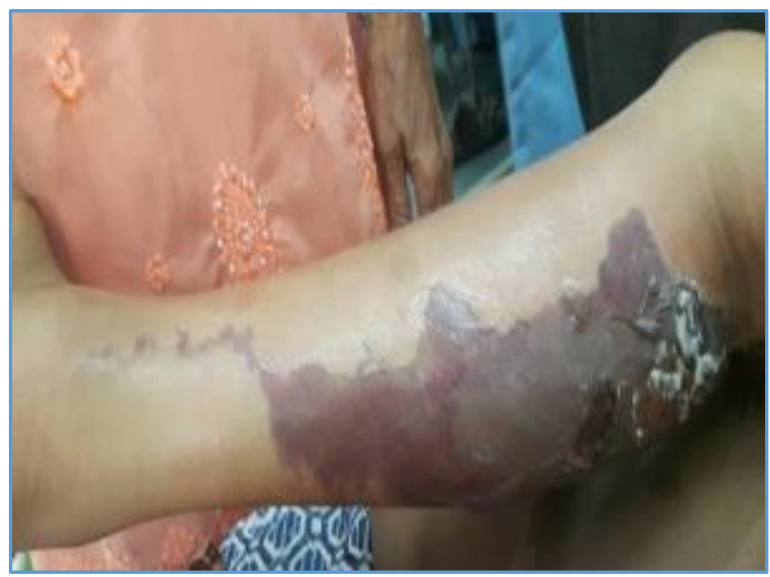

Figure 3 
Her LFT and RFT reports were normal. HIV, HBsAg, HCV and VDRL tests were negative. Colour Doppler of both upper and lower extremities was normal.

Histopathology examination of skin punch biopsy showed epidermal ballooning degeneration and separation at subepidermal level from the underlying dermis. Upper dermis had degeneration of collagen. There was infiltration of medium-sized dermal blood vessels, infiltrate being composed of lymphocytes, neutrophils and plasma cells. In some blood vessels, eosinophilic degeneration of vessel wall was seen. Diffuse haemorrhage around vessels was seen. Biopsy suggestive of medium vessel vasculitis with dermoepidermal necrosis.

Serological tests serum ANA, anti-U1RNP antibody, antiSm antibody, anti-SSA-RO antibody- all were positive. Serum ds-DNA, P-ANCA, C-ANCA, anti-phospholipid antibody, antiSSA-La, anti-Jo-1 antibody, anti-Centromere antibody, antiScl-70 and anticardiolipin antibody all were negative.

\section{Final Diagnosis}

Mixed Connective Tissue Disorder with Vasculitis was done.

\section{Management}

Considering the high leucocyte count on admission a possibility of Purpura Fulminans due to sepsis was also thought about, so systemic steroids were not started immediately on admission.

Patient was started on antibiotics as per culture sensitivity reports. The blood culture sensitivity reports grew Staphylococcus aureus and Klebsiella pneumoniae respectively. Blood culture did not show any growth. She was given Inj. Tazobactam-Piperacillin combination IV 12 hourly for 14 days, Inj. Meropenem 1 gm IV 8 hourly for 10 days, Tab. Forcan $(150 \mathrm{mg})$ for oral candidiasis for 10 days. She was started on Tab. Cyclophosphamide $50 \mathrm{mg}$ daily for 10 days after the diagnosis of MCTD got confirmed, but had to be withheld as her haemoglobin levels fell. The dusky lesions had turned into dry, black and thick crusts. The surrounding oedema had subsided and no new lesions appeared.

She was referred to the General Surgery Department, where debridement of necrotic lesions was done. She received blood transfusion for low Haemoglobin levels.

The dilemma we faced was whether to start steroids under the cover of antibiotics, in this case with large areas of cutaneous necrosis and large deep post debridement ulcers, thereby further potentiating the risk of inducing secondary infection with sepsis or withhold it till the ulcers heal. Histopathology examination of debrided tissue showed fat surrounded by necrotic muscle and hyalinised tissue suggestive of a process akin to necrotising fasciitis. In view of these histopathology findings and after consultation with the surgery department, we decided to withhold systemic steroids.

She later developed chest pain and breathlessness. She was diagnosed with Acute Coronary Syndrome. ECG showed ST changes. 2D Echo revealed mild pericardial effusion, but normal ejection fraction and normal systolic and diastolic function. Her cardiac enzymes were normal. Cardiac catheterisation to rule out pulmonary hypertension could not be done. Patient was started on Atorvastatin, Ecosprin and low molecular weight heparin. Her symptoms improved, but eventually the patient succumbed to her illness after a prolonged hospital stay.

\section{DISCUSSION}

Connective-tissue disease (MCTD) was first recognised by Sharp and Colleagues (1972) in a group of patients with overlapping clinical features of systemic lupus erythematosus (SLE), scleroderma and myositis with the presence of a distinctive antibody against what now is known to be U1ribonucleoprotein (RNP). ${ }^{1,2}$ Common age is $30-50$ yrs. with females predominantly affected with features of SLE, Systemic Sclerosis, Dermatomyositis and Polymyositis. ${ }^{3,4}$ U1Ribonucleoprotein antibody is the specific marker. U1 small nuclear ribonucleoprotein (U1Sn RNP) particle is the target of autoreactive B cells and T cells. ${ }^{1,2}$ Our patient satisfied the Kusukawa diagnostic criteria of MCTD. She had two common symptoms Raynaud's phenomenon and swollen fingers, positive U1 RNP, SLE like finding of pericarditis, sclerodermalike finding of sclerodactyly. ${ }^{5}$ She also satisfied AlarconSegovia Diagnostic criteria for MCTD anti-U1RNP antibody positive and minimum three clinical criteria viz. oedema of hands, Raynaud's phenomenon and acrosclerosis. ${ }^{5}$

Long-term outcome studies have established pulmonary hypertension as the most common disease-related cause of death. ${ }^{6}$ In three prospective studies with 13 - 15 years of followup, MCTD patients had an overall mortality rate of $10.4 \%$ and $20 \%$ of these deaths were directly attributable to cardiac causes. $^{7}$

Vasculitis has been mentioned in MCTD and it often correlates with disease severity and portends poorer prognosis.3,4 Only one case of such a severe form of vasculitis causing tissue necrosis amounting to necrotising fasciitis has been reported. ${ }^{8}$ Necrotising fasciitis is mentioned in connective tissue disorders after prolonged steroid use. ${ }^{9}$ Considering the extensive tissue necrosis and large postdebridement wounds systemic steroids were withheld in our case. She had cardiac symptoms and was worked up and treated for the same. But cardiac catheterisation to rule out pulmonary hypertension could not be performed. Initiating steroids was a therapeutic dilemma, as steroid use has been reported as an aetiological factor in necrotising fasciitis..$^{9,10}$

This was a unique case, which presented with fatal vasculitis resulting in tissue necrosis amounting to necrotising fasciitis and posing a therapeutic dilemma about role of systemic steroids.

\section{REFERENCES}

[1] Sharp GC, Irvin WS, Tan EM, et al. Mixed connective tissue disease--an apparently distinct rheumatic disease syndrome associated with a specific antibody to an extractable nuclear antigen (ENA). Am J Med 1972;52(2):148-59.

[2] Venables P. Mixed connective tissue diseases. Lupus 2006;15(3):132-7.

[3] Goodfield M, Jones SK, Veale DG, et al. The connective tissue disorders. In: Burns $\mathrm{T}$, Breathnach $\mathrm{S}$, Cox $\mathrm{N}$, et al, eds. Rooks textbook of dermatology. Wiley 2010;3(51):110-11.

[4] Amrinder J. Systemic collagen disorders. In: Valia RG, Valia AR, eds. IADVL textbook of dermatology. Mumbai: Bhalani Publishing House 2008;2(36): 1257-8. 
[5] Alarcon-Segovia D, Cardiel MH. Comparison between 3 diagnostic criteria for mixed connective tissue disease. Study of 593 patients. J Rheumatol 1989;16(3):32834.

[6] Burdt MA, Hoffman RW, Deutscher SL, et al. Long-term outcome in mixed connective tissue disease: longitudinal clinical and serologic findings. Arthritis Rheum 1999;42(5):899-909.

[7] Ungprasert P, Wannarong T, Panichsillapakit T, et al. Cardiac involvement in mixed connective tissue disease: a systematic review. Int J Cardiol 2014;171 (3):326-30.
[8] Yuhara T, Takemura H, Akama T, et al. Necrotizing fasciitis caused by Streptococcus pneumoniae in mixed connective tissue disease. Modern Rheumatology 2000;10(3):180-2.

[9] Hashimoto N, Sugiyama H, Asagoe K, et al. Fulminant necrotising fasciitis developing during long term corticosteroid treatment of systemic lupus erythematosus. Ann Rheum Dis 2002;61(9):848-9.

[10] Birkinshaw R, O'Donnell J, Sammy I, et al. Necrotising fasciitis as a complication of steroid injection. J Accid Emerg Med 1997;14(1):52-4. 